Article

\title{
Functionality Study on Light-Weight Ecological Substrate
}

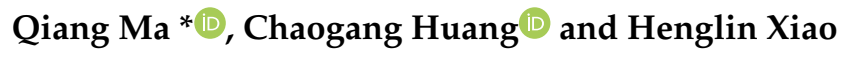 \\ School of Civil Engineering and Architecture, Hubei University of Technology, Wuhan 430068, China; \\ hcg504518118@163.com (C.H.); xiao-henglin@163.com (H.X.) \\ * Correspondence: maqiang927@163.com or 20121012@mail.hbut.edu.cn; Tel.: +86-134-1957-0653
}

Received: 5 November 2018; Accepted: 4 December 2018; Published: 7 December 2018

\begin{abstract}
Dry-sprayed ecological slope protection technology is an effective mean to restore the ecological environment of rock slope, which has been continuously studied and improved by scholars since its advent. Based on the existing research, a new type of dry-sprayed ecological substrate with carbon fiber and expanded polystyrene (EPS) particles was proposed to achieve lightweight and conductive heating. The ingredients of the ecological substrate are EPS, cement, carbon fiber, graphite powder, soil, water-retaining agent, and $\mathrm{pH}$ adjusting agent, respectively. In order to investigate the ecological performance and the physical properties of the substrate, the growth rule of Zoysiagrass was investigated by pot experiment and orthogonal range analysis, and the density and conductivity of the substrate were tested. The result shows that proper EPS particles in the substrate can improve soil structure and promote plant growth, and they play a similar role as soil conditioner. However, when the content of EPS particles exceeds $4 \%$, the substrate is difficult to solidify by cement, which will lead to disintegration. EPS is the main factor affecting the germination and growth of plants, followed by cement, while carbon fiber and graphite powder content effect less. The optimum proportion for plant growth is EPS particle $4 \%$, cement $2.5 \%$, carbon fiber $1 \%$, graphite powder $10 \%, \mathrm{pH}$ adjusting agent $2.5 \%$, and water retaining agent $0.1 \%$. EPS particles can effectively reduce the density of the substrate and thus reduce weight. The average conductivity of the substrate specimens is $384 \Omega \cdot \mathrm{cm}$, which has great conductivity.
\end{abstract}

Keywords: carbon fiber; lightweight substrate; ecological substrate; electrical conductivity; orthogonal test

\section{Introduction}

Landslide is a common geological hazard in life, which is mainly caused by water infiltration and accumulation in the slope [1-3]. Therefore, landslides will be easily caused in heavy rainfall. According to the United States (U.S.) Geological Survey (USGS), thousands of major landslides each year are triggered by rainfall [4]. In order to control landslide, the researchers put forward two kinds of protective measures: civil engineering measures and vegetation engineering measures. The civil engineering measures that were applied to slope protection have a good effect in the initial stage, which can ensure the stability of the slope. However, with the passage of time, concrete gradually ages and steel corrosion intensifies, resulting in a reduction to the strength of protection components and worsening of the protection effect. On the contrary, slope protection with vegetation is relatively weak, but with the vegetation promotion, the role of reducing slope instability and erosion becomes more and more significant, and the environment can be also improved [5-9]. Thus vegetation engineering measures have been strongly advocated in the past few decades.

In the 1970s and 1980s, an ecological slope protection substrate and construction techniques were developed by Japanese researchers [10]. The substrate can be sprayed onto the slope surface to enable 
plants to grow with the help of cement mortar and the metal net laid, just like shotcrete. By adding fiber, doras, and emulsified asphalt, the problem that plants are difficult to grow due to the strong alkalinity of portland cement had been solved [10-12]. In the past few decades, many countries have proved that ecological substrate can effectively promote the combination of vegetation and soil layer with slope surface [13]. Also, some scholars have made research for slope protection in different directions in recent years [14,15]. Ecological substrates have been widely used, but more importantly, the focus of future research will be on multifunctional substrates developing. Little has been done in functionalization. Plants used for slope protection generally have the characteristics of cold resistance, but could still freeze to death, especially in snow and ice rain. Therefore, the main purpose of this study is to propose a new type of ecological substrate that can heat and protect plants from winterkilling in severe cold. There are two questions to consider: (1) heat material and (2) heat preservation. Carbon fibers play a significant role in the manufacture of lightweight composite structures [16]. Also, carbon fiber has many applications in the field of eco-geotechnical engineering. Adding carbon fibers and graphite powder into the substrate can increase the conductivity [17]. Expanded polystyrene (EPS) is a common lightweight material, which is often used in engineering, and also has the effect of heat preservation, which can effectively reduce heat loss in low-temperature environment [18]. Therefore, EPS and carbon fiber are added into the substrate. This paper studied (1) the effect of substrate ingredients on plant growth and the optimum proportion of suitable growth, through the orthogonal pot experiment and (2) the effect of EPS on the density and the conductivity of the substrate after adding carbon fiber and graphite powder, on the basis of a series of laboratory tests.

\section{Materials and Methods}

\subsection{Study Plan}

Through the orthogonal experiment method [19], 16 pots of ecological substrate with different proportions are designed for planting zoysiagrass. Thereafter, germination, growth, and area coverage ratio are monitored. The ecological substrates of different proportion are made into specimens for laboratory tests of density and conductivity.

\subsection{Materials}

The ingredients of ecological substrate include EPS particles, cement, carbon fiber, graphite powder, soil, water-retaining agent, and $\mathrm{pH}$ adjusting agent. Carbon fiber purchased from Toho Chemical Industrial (Shanghai) Co. Ltd., Shanghai, China. Graphite powder purchased from Xieli Graphite Co. Ltd., Dongguan, China. The soil that was used in substrate making has no specific requirement. Here, silt was used. Water-retaining agent was used for storing water for plant growth and $\mathrm{pH}$ adjusting agent was used for reducing alkalinity in cement. The mixture that was used to prepare the specimens for the laboratory test does not include additives as they may or may not be in the field [4]. So it is unnecessary to add these two ingredients into substrate when making specimen for laboratory tests of the physical properties. The physical properties and functions of ingredients are listed in Table 1 . This experiment is to rapidly explore the planting effect of ecological substrate, and only the single species of zoysiagrass (Zoysia tenuifolia Willd. ex Trin) is chosen as the planting object. Zoysiagrass is a kind of important turfgrass and it has some properties, such as freeze tolerance, salt tolerance, and drought resistance, which are of great importance for ecological slope protection [20-22]. 
Table 1. Ingredients and functions of substrate.

\begin{tabular}{ccc}
\hline Ingredients & Materials & Functions \\
\hline EPS & Particles with diameter of 1-3 mm & Lighten substrate, diminish heat loss \\
Cement & Regular Portland cement & Provide adhesive and bonding strength \\
Carbon fiber & Straws with a length of $6 \mathrm{~mm}$ & Strengthen the conductivity of soil [23] \\
Graphite powder & 30 microns in diameter & Assist carbon fiber [24] \\
Water retention agent & $99 \%$ carbon content & Maintain the water for plant growth \\
pH adjusting agent & $0.2 \%$ ferrous sulfate solution & Lower pH value to facilitate plant growth \\
Soil & Silt & Vector for plant growth \\
\hline
\end{tabular}

\subsection{Orthogonal Experimental Design}

The orthogonal experiment method was especially developed to examine the relative significances of multi-variables, as listed in Table 2.

Table 2. Examples for range analysis.

\begin{tabular}{ccccc}
\hline Test\# & Variable A & Variable B & Variable C & $\begin{array}{c}\text { Evaluated } \\
\text { Parameter }\end{array}$ \\
\hline 1 & $\mathrm{~A}_{1}$ & $\mathrm{~B}_{1}$ & $\mathrm{C}_{1}$ & $\mathrm{Y}_{1}$ \\
2 & $\mathrm{~A}_{1}$ & $\mathrm{~B}_{2}$ & $\mathrm{C}_{2}$ & $\mathrm{Y}_{2}$ \\
3 & $\mathrm{~A}_{2}$ & $\mathrm{~B}_{1}$ & $\mathrm{C}_{2}$ & $\mathrm{Y}_{3}$ \\
4 & $\mathrm{~A}_{2}$ & $\mathrm{~B}_{2}$ & $\mathrm{C}_{1}$ & $\mathrm{Y}_{4}$ \\
$\mathrm{k}_{1}$ & $\mathrm{Y}_{1}+\mathrm{Y}_{2}$ & $\mathrm{Y}_{1}+\mathrm{Y}_{3}$ & $\mathrm{Y}_{1}+\mathrm{Y}_{4}$ & \\
$\mathrm{k}_{2}$ & $\mathrm{Y}_{3}+\mathrm{Y}_{4}$ & $\mathrm{Y}_{2}+\mathrm{Y}_{4}$ & $\mathrm{Y}_{2}+\mathrm{Y}_{3}$ & \\
$\mathrm{v}_{\mathrm{i}}$ & 2 & 2 & 2 & \\
$\overline{\mathrm{k}_{1}}$ & $\mathrm{k}_{1} / \mathrm{v}_{\mathrm{i}}$ & $\mathrm{k}_{1} / \mathrm{v}_{\mathrm{i}}$ & $\mathrm{k}_{1} / \mathrm{v}_{\mathrm{i}}$ & \\
$\overline{\mathrm{k}_{2}}$ & $\mathrm{k}_{2} / \mathrm{v}_{\mathrm{i}}$ & $\mathrm{k}_{2} / \mathrm{v}_{\mathrm{i}}$ & $\mathrm{k}_{2} / \mathrm{v}_{\mathrm{i}}$ & \\
\hline Range & \multicolumn{5}{c}{$\mathrm{Max}\left\{\overline{\mathrm{k}_{1}}, \overline{\mathrm{k}_{2}}\right\}-\operatorname{Min}\left\{\overline{\mathrm{k}_{1}}, \overline{\mathrm{k}_{2}}\right\}$} \\
\hline
\end{tabular}

$A_{i}, B_{i}$, and $C_{i}(i=2)$ represent the possible values of Variable $A$, Variable $B$, and Variable $C$, respectively. $A_{1}$ represents the first level(value) of Variable $A$, while $A_{2}$ represents the second level(value). So do subscripts of $B_{i}$ and $C_{i} . k_{1}$ and $k_{2}$, as indicated in Table 2, are the sum of the evaluated parameters related to the first and second possible values of a variable. $\mathrm{R}$ value (the range value), specifying the maximum variation range of $k_{1}$ and $k_{2}$, as indicated in Table 2, can be used to identify the governing factor and optimize the combinations.

As the water-retaining agent that was added in ecological substrate has little influence on plant growth, and the $\mathrm{pH}$ adjusting agent has no direct influence on the growth of zoysiagrass [25], the mass fractions of these two ingredients are given as constant values, and their weights are proportional to the weight of soil and cement, respectively. Based on the experience and a few trials, the contents of each gradient were determined [25]. Therefore, four variables are left: EPS particles, carbon fiber, graphite powder, and cement, and each variable has four possible levels(value). Details were listed in Tables 3 and 4 .

Table 3. Variables and their possible values $w t \%$.

\begin{tabular}{ccccc}
\hline Level & EPS & Fiber & Cement & Graphite Powder \\
\hline 1 & 1 & 1 & 0.25 & 5 \\
2 & 2 & 2 & 0.5 & 10 \\
3 & 3 & 3 & 0.75 & 15 \\
4 & 4 & 4 & 1 & 20 \\
\hline \multicolumn{5}{l}{ Note: values in the table are a percentage by weight of soil. }
\end{tabular}


Table 4. Proportion of ingredient (orthogonal).

\begin{tabular}{ccccccc}
\hline & \multicolumn{5}{c}{ Mass Percentage of Each Material in Substrate/\% } \\
\cline { 2 - 7 } Test\# & EPS & $\begin{array}{c}\text { Carbon } \\
\text { Fiber }\end{array}$ & Cement & $\begin{array}{c}\text { Graphite } \\
\text { Powder }\end{array}$ & $\begin{array}{c}\text { Water Retention } \\
\text { Agent }\end{array}$ & $\begin{array}{c}\text { pH Adjusting } \\
\text { Agent }\end{array}$ \\
\hline 1 & 1 & 1 & 2.5 & 5 & 0.1 & 2.5 \\
2 & 1 & 2 & 5 & 10 & 0.1 & 2.5 \\
3 & 1 & 3 & 7.5 & 15 & 0.1 & 2.5 \\
4 & 1 & 4 & 10 & 20 & 0.1 & 2.5 \\
5 & 2 & 1 & 7.5 & 10 & 0.1 & 2.5 \\
6 & 2 & 2 & 10 & 5 & 0.1 & 2.5 \\
7 & 2 & 3 & 2.5 & 20 & 0.1 & 2.5 \\
8 & 2 & 4 & 5 & 15 & 0.1 & 2.5 \\
9 & 3 & 1 & 10 & 15 & 0.1 & 2.5 \\
10 & 3 & 2 & 7.5 & 20 & 0.1 & 2.5 \\
11 & 3 & 3 & 5 & 5 & 0.1 & 2.5 \\
12 & 3 & 4 & 2.5 & 10 & 0.1 & 2.5 \\
13 & 4 & 1 & 5 & 20 & 0.1 & 2.5 \\
14 & 4 & 2 & 2.5 & 15 & 0.1 & 2.5 \\
15 & 4 & 3 & 10 & 10 & 0.1 & 2.5 \\
16 & 4 & 4 & 7.5 & 5 & 0.1 & \\
\hline
\end{tabular}

\subsection{Germination and Growth Test}

16 circular planting pots $(d=120 \mathrm{~mm}, h=100 \mathrm{~mm})$ were placed to simulate the planting environment in this experiment, as plotted in Figure 1a, which the scale is 1:10. Thereafter, the experiment proceeded with the following steps.

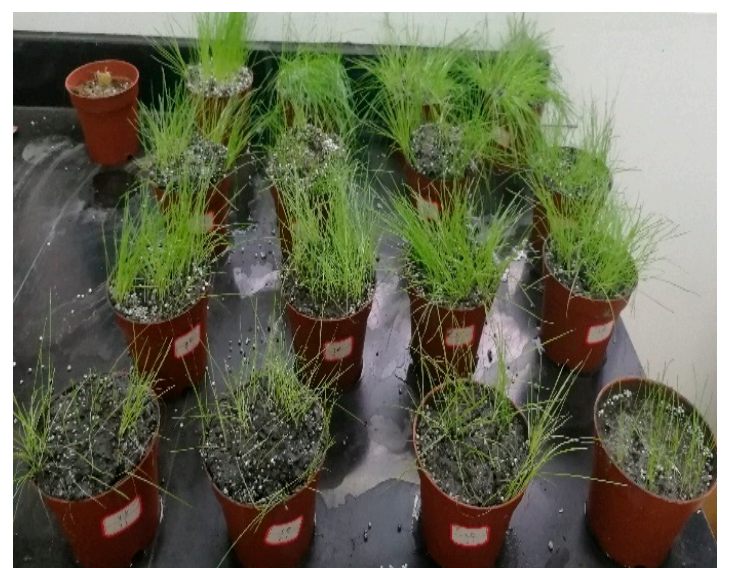

Scale: 1:10

(a)

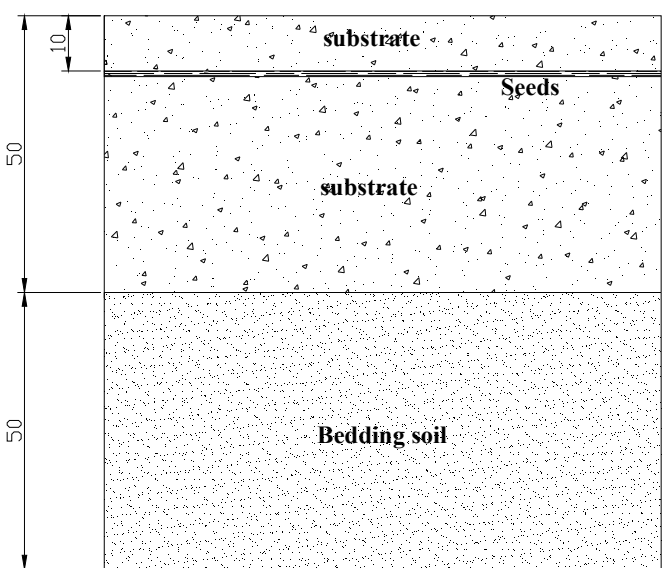

Unit: $\mathrm{mm}$

(b)

Figure 1. (a) Test pots (b) Profile of pots.

The soil was dried in advance and passed through $5 \mathrm{~mm}$ aperture sieve to remove large particle impurities, such as gravel. Loam was buried at the bottom of the planting pot in $50 \mathrm{~mm}$ deep as bedding soil, and the ecological substrate needed for a space of $50 \mathrm{~mm}$ deep on top to plant zoysiagrass. Ecological substrate needed was calculated and weighed by the electronic scale. Ecological substrate ingredients of each pots were mixed uniformly and filled into the corresponding experimental planting pots with appropriate amount of liquid fertilizer. Zoysiagrass seeds were sowed on the layer, $10 \mathrm{~mm}$ from the surface, as shown in Figure 1b. The number of seeds is 200 per pot. The pot was tagged, respectively. The above procedure was applied to every pot.

Germination and growth test begin at 15 July 2018. After sowing, the germination number and seedlings growth height in each pot were continuously monitored and recorded at a certain interval of 
time. In each measurement, 10 seedlings were randomly selected to measure the height, and then the average value was obtained. The total duration was 55 days, till 8 September 2018. The temperature range in planting progress is $22{ }^{\circ} \mathrm{C} 36^{\circ} \mathrm{C}$, and 22 days of rain were recorded until the end of the experiment. According to the dry and wet condition of the substrate, water was poured at morning or dusk. Thereafter, water supply to plants was stopped and all pots were placed outdoor at the day 15 after germinating.

\subsection{Laboratory Tests}

EPS particles, carbon fibers, and graphite powder are added into ecological substrate to make a new functional substrate, so as to protect plants under low temperature and reduce the weight of the substrate. Studying its physical properties is beneficial to investigate the new functionality of the material and provide a basis for the practical application of ecological slope protection. The specimens were made by mold $(d=39.1 \mathrm{~mm} h=80 \mathrm{~mm})$ and cured for seven days. The density and resistivity are measured separately. It should be noted that when the content of EPS particles is $4 \%$, the disintegration of the substrate leads to difficulty in the preparation of the specimen, so in order to ensure the strength of the substrate, EPS content is not suggested to exceed $4 \%$.

\section{Results and Discussion}

\subsection{Germination}

In order to investigate the differences between germination number of each pot, the germination in different days is plotted in Figure 2.

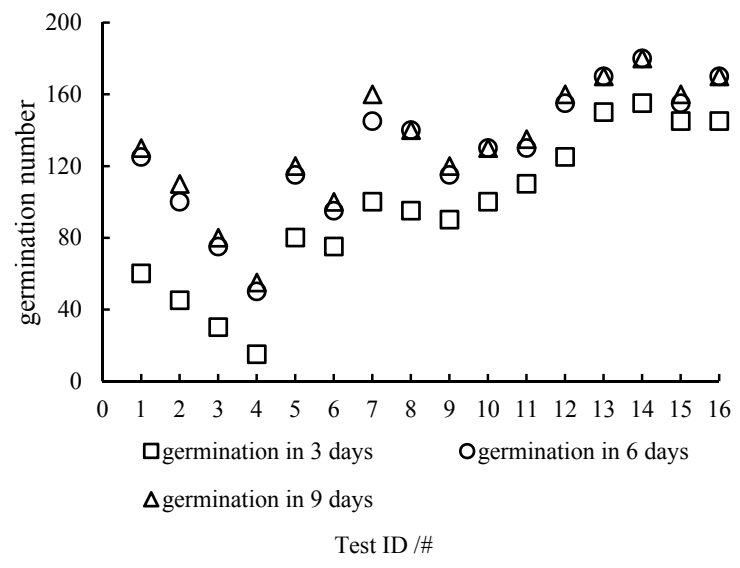

Figure 2. Germination in different days.

Germination was recorded every three days after sowing. Figure 2 shows that at day 3 after sowing, the seeds in all pots have germinated. At day 6 after sowing, the germination number of each pot nearly reaches the maximum. At the day 9 after sowing, the germination number of all pots remains basically unchanged, only a few seedlings die, and the number at the day 9 can be regarded as the maximum. After nine days of growth, the difference of germination in each pot is very obvious. 14\# substrate has the largest germination number, 180 seedlings. In contrast, $4 \#$ substrate has the minimum germination number, 55 seedlings. The ratio of maximum germination number to minimum germination number reached 3.3, and the average germination number is 133 . Germination ratio of $7 \#, 8 \#, 11 \#, 12 \#, 13 \#, 14 \#, 15 \#$, and 16\# are above the average, the others are all below. The germination period of each pot is nearly the same, but the germination number varies greatly. Therefore, the proportion of substrate ingredients has a great correlation with the germination number.

Throughout the whole germination period, when compared with that at day 3 , the germination of $1 \#-4 \#$ pots at the day 6 after sowing increased by $100 \%$ on average, which was the greatest in the other 
pots. The germination of $5 \#-8 \#$ pots increased by $50 \%$, which was relatively flat. The germination of 9\#-16\# substrate increased by only $20-30 \%$, which the increase rate was slow.

In order to investigate the effect of ingredients on germination, the relationship between the ingredients content and germination ratio is plotted in Figure 3. The germination ratio is obtained from dividing the seeds number in every pot by seedling number in day 9 .

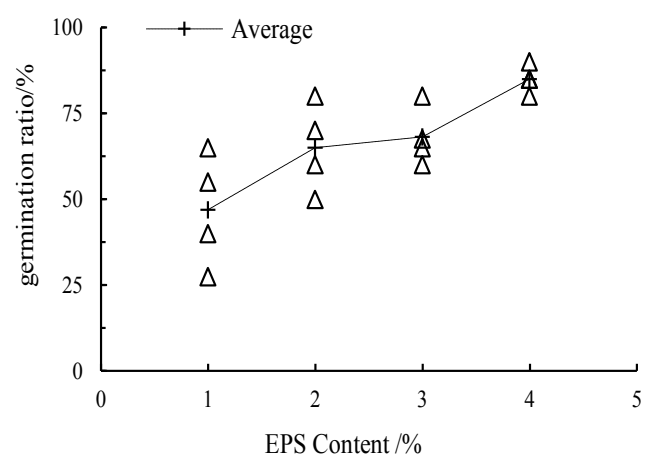

(a)

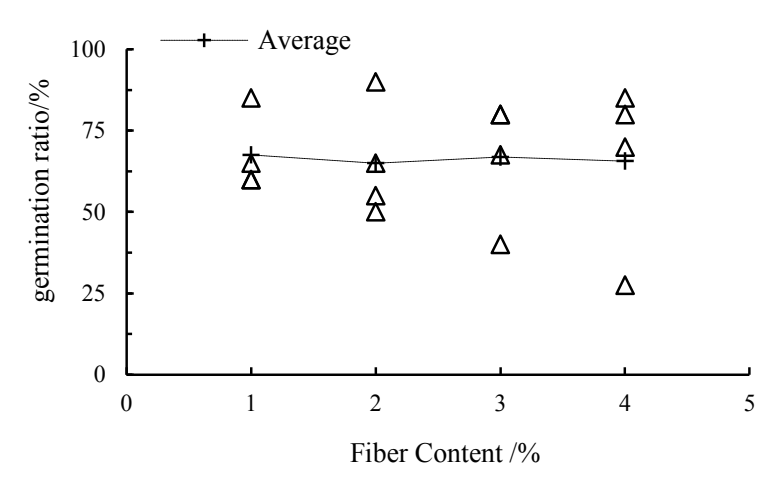

(c)

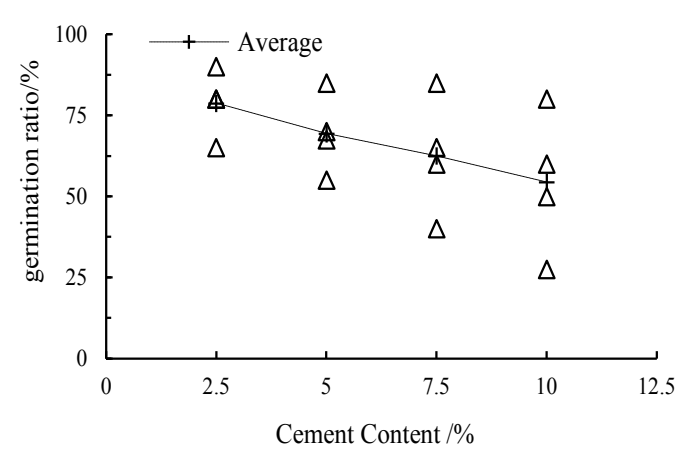

(b)

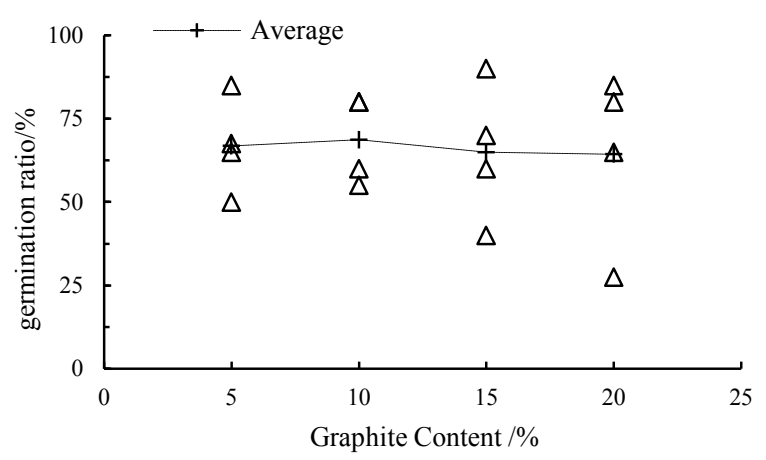

(d)

Figure 3. (a) Germination vs EPS Content (b) Germination vs Cement Content (c) Germination vs Fiber Content (d) Germination vs Graphite Content.

As plotted in Figure 3a,b, obviously, with the increase of EPS content, the germination ratio is increasing, while, with the increase of cement content, the germination ratio is decreasing. The increase of EPS content promotes germination in general, resulting in an increase of 13 percent ( 26 seedlings) in the germination ratio for every 1 percent increase in EPS content. Cement hinders the germination, and the relationship between cement content and germination ratio represents a decreasing linear relationship, which the germination ratio decreases 3.5 percent (seven seedlings) for every 1 percent increase in cement content.

As plotted in Figure $3 c$, d, there is no obvious relationship between fiber content, graphite content and germination ratio, respectively. According to the average germination ratio, it is found that with the increase of fiber content and graphite content, the germination ratio keeps an almost constant value, which shows that the effect of fiber content and graphite content of substrate on the germination ratio is not significant.

In order to investigate the effect of ingredients to germination, range analysis for germination was carried out, as listed in Table 5. The EPS particle was the dominating factor affecting plant germination, followed by cement. Graphite powder and carbon fiber had little effect on the germination of zoysiagrass. From the above data, when the EPS content is $1 \%$, the cement solidification effect is obvious, which results in the stable internal structure of substrate. On the contrary, when the content of EPS is over 1\%, the contact surface between EPS particles increases, resulting in the available space for seeds increasing. The cement solidification effect is greatly dispersed, which is similar to soil 
conditioner to adjust the internal structure of substrate. As for the little effect of carbon fiber and graphite, the possible reason is that carbon fiber and graphite powder are an inert material without chemical reflection, and it is difficult to achieve the effect of EPS in the form of discrete materials. In addition, may the $\mathrm{pH}$ adjusting agent does not take full effect at day 3 , the alkalinity of the substrate is strong. With time, the internal environment of the substrate becomes more and more stable, and the adaptability of the zoysiagrass seeds gradually increase, which cause the germination rate increase at day 3 after sowing. Therefore, the germination ratio of $9 \#-16 \#$ in first three days is higher than that of $1 \#-8 \#$, but the germination ratio in next three days is lower than that of $1 \#-8 \#$ because of its large germination base number.

Table 5. Range analysis for germination.

\begin{tabular}{cccccc}
\hline Test\# & EPS & Carbon Fiber & Cement & Graphite Powder & Germination \\
\hline 1 & 1 & 1 & 1 & 1 & 130 \\
2 & 1 & 2 & 2 & 2 & 110 \\
3 & 1 & 3 & 3 & 3 & 80 \\
4 & 1 & 4 & 4 & 4 & 55 \\
5 & 2 & 1 & 3 & 2 & 120 \\
6 & 2 & 2 & 4 & 1 & 100 \\
7 & 2 & 3 & 1 & 4 & 140 \\
8 & 2 & 4 & 2 & 3 & 120 \\
9 & 3 & 1 & 4 & 3 & 130 \\
10 & 3 & 2 & 3 & 4 & 160 \\
11 & 3 & 3 & 2 & 1 & 170 \\
12 & 3 & 4 & 1 & 2 & 160 \\
13 & 4 & 1 & 2 & 4 & 170 \\
14 & 4 & 2 & 1 & 3 & \\
15 & 4 & 3 & 4 & 2 & \\
16 & 4 & 4 & 3 & 1 & \\
\hline$\overline{\mathrm{k}_{1}}$ & 94 & 135 & 158 & 134 & \\
\hline $\mathrm{k}_{2}$ & 130 & 130 & 139 & 138 & \\
\hline $\mathrm{k}_{3}$ & 136 & 134 & 125 & 130 & \\
\hline $\mathrm{k}_{4}$ & 170 & 131 & 108 & 128 & \\
\hline Range & 76 & 5 & 49 & 10 & \\
\hline
\end{tabular}

\subsection{Growth}

\subsubsection{Growth Rate}

From the beginning of germination, the growth height in each pot was measured at set intervals. Different proportions of substrates lead to different growth states, but to a certain extent, they still show a similar growth rhythm. The whole growth period can be divided into three phases, as plotted in Figure 4.

Germination phase (Phase I): within nine days after sowing, the plants in all pots grow slowly, and the growth height is no more than $5 \mathrm{~cm}$, with an average of $2.7 \mathrm{~cm}$. Among them, growth height of $4 \#$ is the lowest, only $1.4 \mathrm{~cm}$, while, 14\# is the highest, reaching $4.6 \mathrm{~cm}$.

Growth phase (Phase II): starting from the day 9, Zoysiagrass enter the first rapid growth phase, which lasts about 20 days. The time for different pots to enter the rapid growth stage is different. The average height of Zoysiagrass grows to $14.6 \mathrm{~cm}$, with an average height of $14.7 \mathrm{~cm}$. The $13 \#$ and $4 \#$ are $205 \mathrm{~mm}$ and $76 \mathrm{~mm}$, respectively. The height difference is $13 \mathrm{~cm}$. The growth heights of all pots have obvious changes. The average of pots 1\#-4\# in day 30 is $9.7 \mathrm{~cm}$, while it was $1.75 \mathrm{~cm}$ at day 9 , which increases by $450 \%$. Similarly, pots $5 \#-8 \#, 9 \#-12 \#$ and $13 \#-16 \#$ increase by $480 \%, 420 \%$ and $380 \%$, respectively. As $1 \#-8 \#$ enter the growth phase a little later, although the growth rate is 
significantly higher than 9\#-16\#, the overall growth height is still below the average level. At this phase, the difference in growing height of each substrate is more and more obvious.

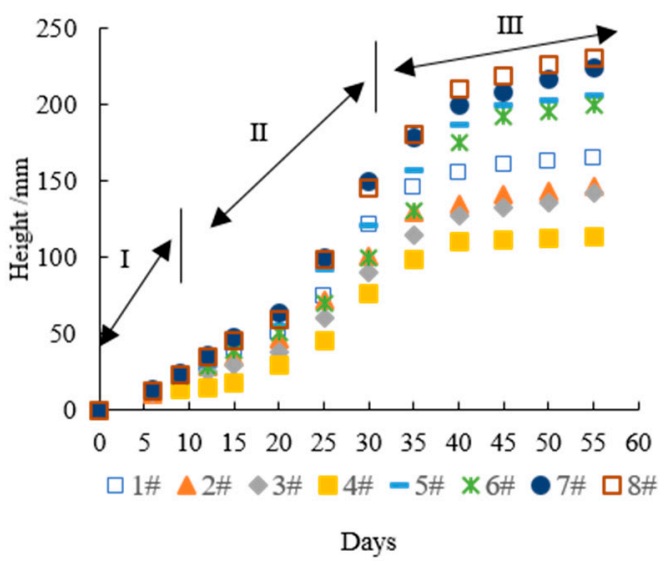

(a)

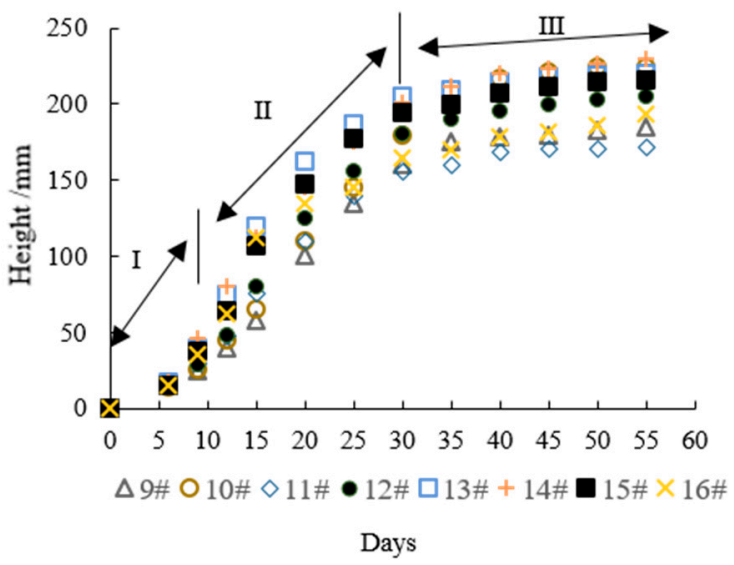

(b)

Figure 4. (a) Growth height vs Days of 1\# 8\# (b) Growth height vs Days of 9\# 16\#.

Steady phase (Phase III): 30 days to 55 days after sowing, the growth curve of each pot begins to smooth, with growth fluctuations decreasing. There are still some pots of zoysiagrass maintain rapid growth, however, only for a few days. The average growth height is $19.2 \mathrm{~cm}$, which is about $30 \%$ higher than the Phase II. The vegetation of ecological slope protection is liable to be eroded and destroyed at the early stage of its growth. However, after 40 days of outdoor planting, there is no obvious water erosion on the surface of the substrate. It is preliminarily judged that the root system of Zoysiagrass has preliminarily possessed a certain ability of soil consolidation, and it can resist the destruction of external environment such as rain erosion.

Because the growth phase is the fastest growing period of Zoysiagrass, the growth height of Zoysiagrass on the 30th day was taken for range analysis to analyze the effects of ingredients on the growth of Zoysiagrass. It can be seen that the order of Table 6 is slightly different from that of Table 4, but EPS and cement contents are still the main factors affecting the growth of Zoysiagrass, and the effect of carbon fiber and graphite powder is enhanced. The relationship between EPS content and growth height is plotted in Figure 5. According to Figure 5, a positive relationship between EPS content and growth height can be determined. However, EPS particles do not have any chemical relationship with plant growth, so the effect of EPS particles on plant growth height would be similar to that of other components. In order to determine the relationship between EPS content and growth height, further experiments are needed.

Table 6. Range analysis for growth.

\begin{tabular}{ccccc}
\hline Test\# & EPS (\%) & Carbon Fiber (\%) & Cement (\%) & Graphite Powder (\%) \\
\hline$\overline{\mathrm{k}_{1}}$ & 97 & 151.75 & 163 & 135.5 \\
$\overline{\mathrm{k}_{2}}$ & 129 & 145.5 & 151.75 & 149.25 \\
$\overline{\mathrm{k}_{3}}$ & 169 & 147.75 & 139 & 149 \\
$\overline{\mathrm{k}_{4}}$ & 191.5 & 141.5 & 132.75 & 152.75 \\
\hline Range & 94.5 & 10.25 & 30.25 & 17.25 \\
\hline
\end{tabular}




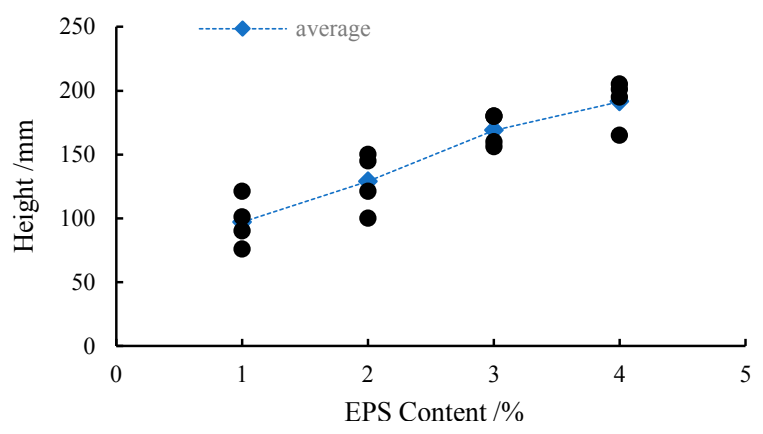

Figure 5. Relationship between growth height and expanded polystyrene (EPS) content.

\subsubsection{Area Coverage Ratio}

The coverage is calculated by the projection area of the plant stem and leaves to the ground. A high-resolution camera took a photo of a cell area, which was then imported into a photo processing software. For each pot, the projection area of the plant stem and leaves is measured and divided by the projection area of the substrate [26]. The area coverage ratio of each pot is recorded for 55 days, as plotted in Figure 6. The coverage of substrates varies greatly. Pot 13 and 14 have 100\% coverage, while the lowest area coverage ratio of 4 is only $25 \%$, and most of the rest are over $50 \%$ coverage. Still, in the range analysis for area coverage ratio of Table 7, EPS content is the dominant factor affecting the area coverage ratio. Usually, the higher plants are, the more leaves will be. EPS is the main factor affecting the growth height, which promotes the growth height in Figure 5. Therefore, maybe the effect of EPS on area coverage ratio is a false appearance derived from the effect of EPS on growth height. Because the overlap of plant leaves is not considered in the coverage measurement, the higher the plants are, the more significant the overlap of plant leaves will be. Measurement results of area coverage ratio cannot accurately reflect the effect of ingredients on growth, and this explains why growth height being used to describe the quality of plant growth will be better.

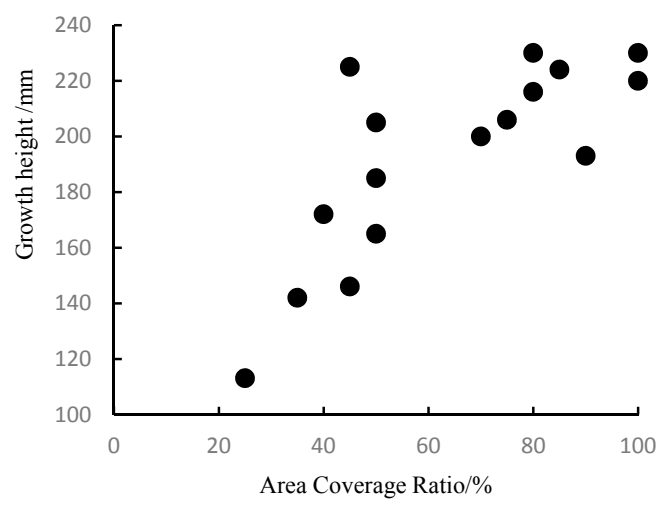

Figure 6. Area coverage ratio of each pot.

Table 7. Range analysis for area coverage ratio.

\begin{tabular}{ccccc}
\hline Test\# & EPS (\%) & Carbon Fiber (\%) & Cement (\%) & Graphite Powder (\%) \\
\hline$\overline{\mathrm{k}_{1}}$ & 38.75 & 68.75 & 71.25 & 62.5 \\
$\overline{\mathrm{k}_{2}}$ & 77.5 & 65 & 66.25 & 62.5 \\
$\overline{\mathrm{k}_{3}}$ & 53.75 & 60 & 61.25 & 66.25 \\
$\overline{\mathrm{k}_{4}}$ & 92.5 & 61.25 & 56.25 & 63.75 \\
\hline Range & 53.75 & 8.75 & 15 & 3.75 \\
\hline
\end{tabular}




\subsection{Integrated Range Analysis}

Selecting the maximum germination, the final area coverage ratio and the growth height of the 30 days as three indicators to composite scores, with $40 \%, 30 \%, 30 \%$ weights, respectively [27]. A range analysis of composite scores is performed, as plotted in Table 8 .

Table 8. Range analysis of composite scores.

\begin{tabular}{|c|c|c|c|c|c|c|c|}
\hline Test\# & $\begin{array}{c}\text { Coverage } \\
\text { Ratio }\end{array}$ & Scores (A) & $\begin{array}{l}\text { Growth } \\
\text { Height }\end{array}$ & Scores (B) & Germination & Scores (C) & $\begin{array}{c}\text { Composite } \\
\text { Scores }\end{array}$ \\
\hline 1 & 50 & 50 & 51 & 31 & 130 & 72 & 51 \\
\hline 2 & 45 & 45 & 46 & 28 & 110 & 61 & 45 \\
\hline 3 & 35 & 35 & 38 & 23 & 80 & 44 & 34 \\
\hline 4 & 25 & 25 & 30 & 18 & 55 & 34 & 26 \\
\hline 5 & 75 & 75 & 55 & 34 & 120 & 67 & 60 \\
\hline 6 & 70 & 70 & 51 & 31 & 100 & 56 & 54 \\
\hline 7 & 85 & 85 & 63 & 39 & 160 & 89 & 72 \\
\hline 8 & 80 & 80 & 59 & 36 & 140 & 78 & 66 \\
\hline 9 & 50 & 50 & 101 & 62 & 120 & 67 & 59 \\
\hline 10 & 45 & 45 & 110 & 68 & 130 & 72 & 60 \\
\hline 11 & 40 & 40 & 110 & 68 & 135 & 75 & 59 \\
\hline 12 & 50 & 50 & 125 & 77 & 160 & 89 & 70 \\
\hline 13 & 100 & 100 & 163 & 100 & 170 & 94 & 98 \\
\hline 14 & 100 & 100 & 145 & 89 & 180 & 100 & 97 \\
\hline 15 & 80 & 80 & 148 & 91 & 160 & 89 & 86 \\
\hline 16 & 90 & 90 & 135 & 83 & 170 & 94 & 89 \\
\hline & & EPS (\%) & & \multicolumn{2}{|c|}{ Carbon Fiber (\%) } & $\begin{array}{c}\text { Cement } \\
(\%)\end{array}$ & $\begin{array}{c}\text { Graphite } \\
\text { Powder (\%) }\end{array}$ \\
\hline$\overline{\mathrm{k}_{1}}$ & & 39 & & \multicolumn{2}{|c|}{67} & 72.5 & 63.25 \\
\hline$\overline{\mathrm{k}_{2}}$ & & 63 & & \multicolumn{2}{|c|}{64} & 67 & 65.25 \\
\hline$\overline{\mathrm{k}_{3}}$ & & 62 & & \multicolumn{2}{|c|}{62.75} & 60.75 & 64 \\
\hline$\overline{\mathrm{k}_{4}}$ & & 92.5 & & \multicolumn{2}{|c|}{62.75} & 56.25 & 64 \\
\hline Range & & 53.5 & & \multicolumn{2}{|c|}{4.25} & 16.25 & 2 \\
\hline
\end{tabular}

According to the range, the factors affecting the growth of Zoysiagrass are EPS, cement, fiber, and graphite, in turn. $K_{4}=92.5$ in different content of EPS is the largest (taking the maximum of $k_{1}$, $\mathrm{k}_{2}, \mathrm{k}_{3}, \mathrm{k}_{4}$ ), therefore, EPS should take the 4 th level, that is, the weight ratio of $4 \%$. Similarly, $\mathrm{K}_{1}$ in different content of cement is the largest, the optimal content of $2.5 \%$. $\mathrm{K}_{1}$ in different content of fiber is the largest, the optimal content of $1 \%, \mathrm{~K}_{2}$ in different content of graphite is the largest, the optimal content of $10 \%$.

In summary, the optimum proportion for the growth of Zoysiagrass is EPS particle $4 \%$, cement $2.5 \%$, carbon fiber $1 \%$, and graphite powder $10 \%$.

\subsection{Density Test}

The specimen was weighed by an electronic scale with a precision of $0.01 \mathrm{~g}$ and the density of the specimen was calculated. The relationship between EPS content and the density of the substrate was plotted under different cement content, as plotted in Figure 7.

According to Figure 7, the density of substrate decreases with the increase of EPS content. Taking the curve of cement content of $5 \%$ as an example, the average density of EPS is $1 \%$ per increase of $0.3 \mathrm{~g} / \mathrm{cm}^{3}$. The content of EPS increases from $1 \%$ to $4 \%$, and the overall density decreases by about $50 \%$. The other three curves also have similar trends. It can be seen that the incorporation of EPS has a very significant impact on the overall lightening of the substrate. In the practical application of ecological slope protection, the purpose of lightening can be achieved by adding appropriate EPS. Under the same EPS content, the cement content increases from $2.5 \%$ to $10 \%$, and the overall density difference only changes less than $0.3 \mathrm{~g} / \mathrm{cm}^{3}$, which increases little and can be indicated that the influence of 
cement content on density is weak. When the cement content is relatively small, the impact on density is negligible.

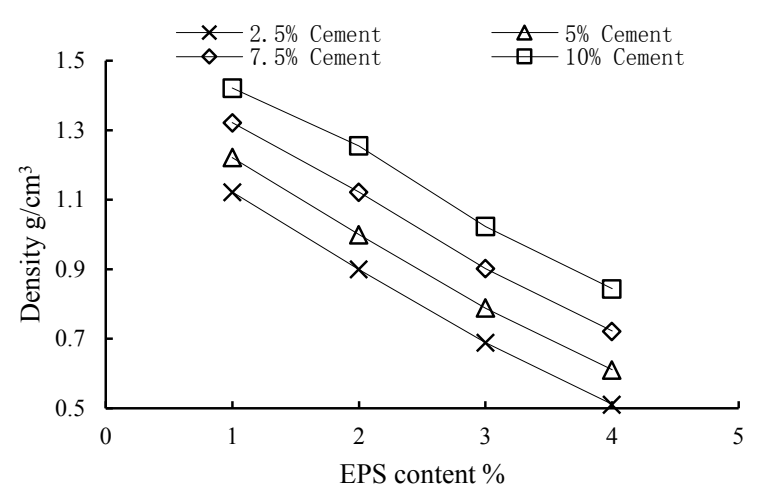

Figure 7. Relationship between EPS content and the density under different cement content.

\subsection{Resistivity Test}

The resistivity of the specimen was measured by the two-electrode method [28], where a TH2817A Precision LCR Meter (Langpu electronics technology co. LTD, Shenzhen, China) was used. Figure 8 shows the relationship between resistivity and carbon fiber under different EPS content levels. Because EPS particles are insulating materials, excessive addition of EPS particles can dramatically increase the resistance of the substrate, but that of carbon fiber has the opposite effect. Therefore, the resistivity of the substrate increases with the increase of EPS content, and decreases with the increase of carbon fiber content. The minimum resistivity of the sample is less than $100 \Omega \cdot \mathrm{cm}$, and the maximum resistivity is $817 \Omega \cdot \mathrm{cm}$, with an average of $384 \Omega \cdot \mathrm{cm}$, which is equivalent to the resistivity of conductive heating materials that are commonly used in engineering [29]. It can be seen that the substrate in cold and harsh environment using electric energy to protect plants is very promising.

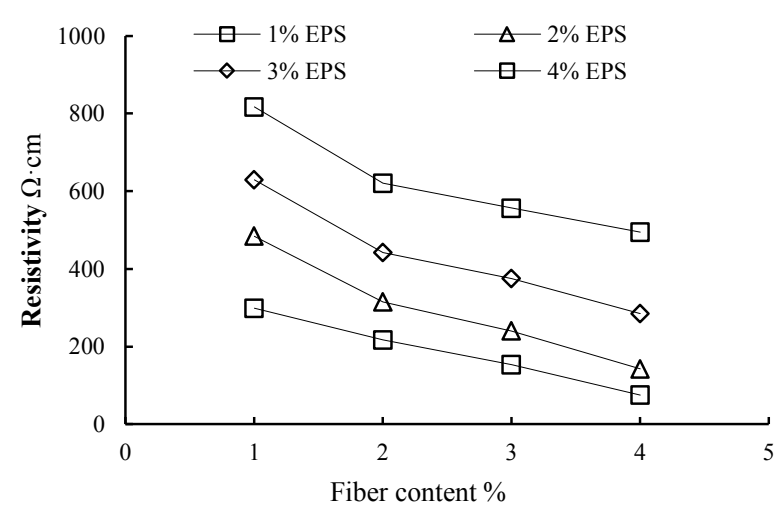

Figure 8. Relationship between fiber content and the resistivity under different EPS content.

\section{Conclusions}

(1) EPS particles can succeed soil conditioner to improve soil structure and promote plant growth, but the content should not exceed $4 \%$.

(2) According to the all range analysis, the factors affecting the growth of Zoysiagrass are EPS, cement, fiber and graphite in turn.

(3) The optimum proportion is obtained by range analysis: EPS particle $4 \%$, cement $2.5 \%$, carbon fiber $1 \%$, graphite powder $10 \%, \mathrm{pH}$ adjusting agent $2.5 \%$, and water retaining agent $0.1 \%$.

(4) The overall density of the substrate decreases significantly with the addition of EPS, but the influence of cement content on the density is not obvious. 
(5) The addition of carbon fiber and graphite significantly improves the conductivity of the substrate. The average resistivity measured by the substrate is $384 \Omega \cdot \mathrm{cm}$. Conductive heating can be considerable.

In this paper, the substrate has excellent performance in ecological function and physical properties, and it made a breakthrough in lightening and electric heating. The scoring of the comprehensive indexes of the 11 kinds of proportions is above 60, which can be extended to practical application, and the obtained rules can also be applied to the study of the proportioning of similar ecological slope protection substrates.

Author Contributions: Q.M. is responsible for the idea providing and the paper revision. C.H. is responsible for the experimental process and the manuscript writing. H.X. is responsible for the experiment directing.

Funding: This research was funded by National Key R\&D Program of China [Grant No. 2016YFC0502208], National Natural Science Foundation of China (NSFC) [Grant Nos. 51678223, 51608181], University Outstanding Youth Science and Technology Innovation Team Project in Hubei Province [Grant No. T201605], Hubei Provincial Education Department Key Project [Grant No. D20171402], and Green Industrial Project of Hubei University of Technology [Grant Nos. YXQN2017001, BSQD12153].

Acknowledgments: The authors would like to express their appreciation to these financial assistances.

Conflicts of Interest: I, the corresponding author, am responsible for coauthors declaring their interests, and I declare that there is no conflict of interest regarding the publication of this article.

\section{References}

1. Baum, R.L.; Johnson, A.M. Overview of Landslide Problems, Research, and Mitigation, Cincinnati, Ohio, Area; US Government Printing Office: Washington, DC, USA, 1996; 36p.

2. Turner, A.K.; Schuster, R.L. Landslides: Investigation and Mitigation; National Academy of Sciences: Washington, DC, USA, 1996; 673p.

3. Highland, L.; Bobrowsky, P.T. The Landslide Handbook: A Guide to Understanding Landslides; US Geological Survey: Reston, FL, USA, 2008.

4. Xiao, H.; Huang, J.; Ma, Q.; Wan, J.; Li, L.; Peng, Q.; Rezaeimalek, S. Experimental study on the soil mixture to promote vegetation for slope protection and landslide prevention. Landslides 2017, 14, 287-297. [CrossRef]

5. Gray, D.H.; Leiser, A.T. Biotechnical Slope Protection and Erosion Control; Nostrand Reinhold Co.: New York, NY, USA, 1982; Volume 10, pp. 77-78.

6. Lee, I.W.Y. A Review of Vegetative Slope Stabilization; Hong Kong Inst. of Engineer: Hong Kong, China, 1985; Volume 13, pp. 9-12.

7. Freer, R. Bio-engineering: The use of vegetation in civil engineering. Constr. Build. Mater. 1991, 5, 23-26. [CrossRef]

8. Cammeraat, E.; van Beek, R.; Kooijman, A. Vegetation succession and its consequences for slope stability in SE Spain. Plant Soil 2005, 278, 135-147. [CrossRef]

9. Stokes, A.; Norris, J.E.; Van Beek, L.P.H.; Bogaard, T.; Cammeraat, E.; Mickovski, S.B.; Jenner, A.; Di Iorio, A.; Fourcaud, T. How Vegetation Reinforces Soil on Slopes. In Slope Stability and Erosion Control: Ecotechnological Solutions; Springer: Dordrecht, The Netherlands, 2008; pp. 65-118.

10. Jianjun, Y.; Mingtao, Z.; Wennian, X. Discussion on Material Spraying Methods of Slope Protection and Revegetation. Res. Soil Water Conserv. 2004, 11, 194-197. (In Chinese)

11. Geng, X.; Chen, K.S.; Gao, R.F.; Toyoda, Y. Enlightenment on Roads Restoration in Lushan-Earthquake-Stricken Areas from Japanese Slope Afforestation Technology. Appl. Mech. Mater. 2013, 368, 1657-1662. [CrossRef]

12. Sata, V.; Tangpagasit, J.; Jaturapitakkul, C.; Chindaprasirt, P. Effect of W/B ratios on pozzolanic reaction of biomass ashes in Portland cement matrix. Cem. Concr. Compos. 2012, 34, 94-100. [CrossRef]

13. Martin, R.P. Panelist report-Landscaping and bio-engineering of slopes in Hong Kong, geotechnical engineering: Meeting societies needs. In Proceedings of the 14th Southeast Asian Geotechnical Conference, Hong Kong, China, 10-14 December 2001; pp. 661-670.

14. Bao, X.; Liao, W.; Dong, Z.; Wang, S.; Tang, W. Development of Vegetation-Pervious Concrete in Grid Beam System for Soil Slope Protection. Materials 2017, 10, 96. [CrossRef] [PubMed]

15. Guoqing, L.; Lei, L.; Yuntian, W. Application of New Slope Greening Technology-Reinforced OrganicMaterial and Plant Seeds Spraying. Agric. Sci. Technol. 2014, 15, 152-154. 
16. Nunna, S.; Maghe, M.; Fakhrhoseini, S.M.; Polisetti, B.; Naebe, M. A Pathway to Reduce Energy Consumption in the Thermal Stabilization Process of Carbon Fiber Production. Energies 2018, 11, 1145. [CrossRef]

17. Liu, X.; Wu, S. Study on the graphite and carbon fiber modified asphalt concrete. Constr. Build. Mater. 2011, 25, 1807-1811. [CrossRef]

18. Rashid, Y.; Alnaimat, F.; Mathew, B. Energy Performance Assessment of Waste Materials for Buildings in Extreme Cold and Hot Conditions. Energies 2018, 11, 3131. [CrossRef]

19. Wu, C.F.J.; Hamada, M. Experiments: Planning, Analysis, and Parameter Design Optimization; Wiley: Hoboken, NJ, USA, 2002; 760p.

20. Patton, A.J.; Reicher, Z.J. Zoysiagrass Species and Genotypes Differ in Their Winter Injury and Freeze Tolerance. Crop Sci. 2007, 47, 1619-1627. [CrossRef]

21. Qian, Y.L.; Engelke, M.C.; Foster, M.J.V. Salinity effects on zoysiagrass cultivars and experimental lines. Crop Sci. 2000, 40, 488-492. [CrossRef]

22. White, R.H.; Engelke, M.C.; Anderson, S.J.; Ruemmele, B.A.; Marcum, K.B.; Taylor, G.R. Zoysiagrass Water Relations. Crop Sci. 2001, 41, 133-138. [CrossRef]

23. Chakrabarti, K.; Nambissan, P.M.G.; Mukherjee, C.D.; Bardhan, K.K.; Kim, C.; Yang, K.S. Positron annihilation spectroscopy of polyacrylonitrile-based carbon fibers embedded with multi-wall carbon nanotubes. Carbon 2006, 44, 948-953. [CrossRef]

24. Xian, W.U.; Cui, Y.; Hui, G. Experimental Study on the Electro-Thermal Behavior of Conductive Concretes with Carbon Black and Carbon Fiber-Carbon Black. J. Shenyang Jianzhu Univ. 2015, 31, 449-457. (In Chinese)

25. Xiao, H.; Ma, Q.; Ye, J.; Wan, J.; Li, L.; Peng, Q. Optimization on formulation of peat-fiber-cement-based dry-sprayed substrate for slope ecological protection by site experiment. Trans. Chin. Soc. Agric. Eng. 2015, 31, 221-227. (In Chinese)

26. Datt, B.; Paterson, M. Vegetation-soil spectral mixture analysis. In Proceedings of the IEEE 2000 International Geoscience and Remote Sensing Symposium, Honolulu, HI, USA, 24-28 July 2000; Volume 5, pp. 1936-1938.

27. Xiao, H.; Li, G. Analysis on the present situation of slope eco engineering. J. Hunan Univ. Nat. Sci. Ed. 2008, 35, 213-216. (In Chinese)

28. Yang, Q.; Li, X.; Wang, P. Resistivity measurement of conductive asphalt concrete based on two-electrode method. J. Cent. South Univ. 2013, 20, 2599-2604. [CrossRef]

29. Wu, J.; Liu, J.; Yang, F. Three-phase composite conductive concrete for pavement deicing. Constr. Build. Mater. 2015, 75, 129-135. [CrossRef]

(C) 2018 by the authors. Licensee MDPI, Basel, Switzerland. This article is an open access article distributed under the terms and conditions of the Creative Commons Attribution (CC BY) license (http://creativecommons.org/licenses/by/4.0/). 